\title{
Chronic Cystitis
}

National Cancer Institute

\section{Source}

National Cancer Institute. Chronic Cystitis. NCI Thesaurus. Code C27008.

Recurrent infections of the urinary bladder. 